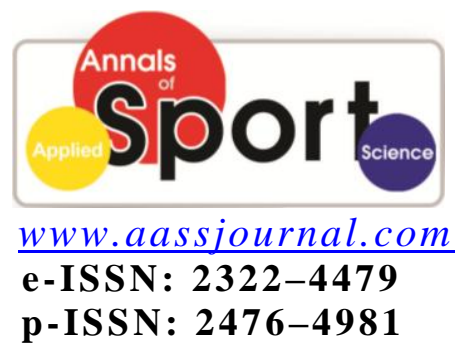

Driginal Article

Received: $16 / 07 / 2014$

Accepted: 01/12/2014

\title{
Relationship between Trait and State Anxiety with Force Control and Accommodation of Dominant Hand's Angle in Male Students
}

\section{${ }^{1}$ Mohammad Moradi*, ${ }^{2}$ Asghar Ghorbani, ${ }^{2}$ Mehdi Yazdanpanah, ${ }^{2}$ Ghorbanali Javan Eghbal Tajeddin, ${ }^{1}$ Alireza Bahrami}

1. Department of Physical Education and Sport Science, Arak University, Arak, Iran.

2. Department of Physical Education and Sport Science, Allameh Tabataba'i University, Tehran, Iran.

\begin{abstract}
The aim of this study was to study the relationship between trait and state anxiety with force control and adjustment of dominant hand's angle in male athlete and non-athlete students. For this purpose, 200 students (100 athletes and 100 non-athletes) where randomly selected among all male bachelor students of Arak University in the academic year 2012-2013 by simple random method. The mean age of subjects was $21.80 \pm 1.96$. The required data were collected using personal information questionnaire, Spielberger state-trait anxiety inventory (STAI), Zhukovski's dominant hand's angle accommodation test, and Ablacova's force control of dominant hand test. The findings showed that there is a strong and positive correlation between trait and state anxiety and kinesthesia in both of the groups. There results also showed that kinesthesia error can predict the trait anxiety $(\mathrm{p}=0.041)$ and state anxiety $(\mathrm{p}=0.011)$. Study findings indicated that there is a significant relationship between trait and state anxiety and kinesthesia. In addition, non-athletes showed higher levels of anxiety and hallucination. According to the moderate levels of state anxiety in athletes, it can be stated that this study supports the inverted U hypothesis.
\end{abstract}

Key Words: Kinesthesia, Inverted U hypothesis, Trait Anxiety, State Anxiety.

Corresponding Author:

Mohammad Moradi

E-mail: m_moradi111@yahoo.com 


\section{INTRODUCTION}

Anxiety is one of the important psychological factors that greatly affect the performance of athletes, especially in crucial situations. Anxiety implies a sense of insecurity or threat that its source is not clearly understood (1). Anxiety is the negative emotional state with feelings of anger, sadness, and tension caused by a disturbing environment and is associated with physical activity or arousal (2). Anxiety in sport reflects the fears of an athlete that something would go wrong and he/she fails to perform as expected (2). The ability to cope with stress and anxiety is an integral part of sport (3). Many studies have been conducted on the relationship between anxiety and performance in sports competitions.

Competitive anxiety is one of the types of anxiety that has attracted the attention of sport psychology researchers. This type of anxiety, also known as Trait-state anxiety, occurs during sports competitions (3, 4). Martens, Vealey, and Burton (1990) defined this type of anxiety as the tendency to perceive competitive situations as a threatening factor and responding to such situations is associated with a sense of anxiety or tension (5). In other words, anxiety is a relatively stable and acquisitive behavioral tendency which is often described as a personality feature. The anxiety response occurring in certain competitive situations is called state-competitive anxiety. Even professional athletes who have high anxiety, compare with those who a lower level of anxiety, show a dramatic increase in physiological arousal in a state of anxiety, so they are more likely to fail to present a perfect performance (5). Studies have shown that optimal increase in arousal improves performance, but its excessive increase would lead to reduced proficiency in motor function (4-6). Several studies have indicated that trait-state anxiety can affect athletic performance. In other words, the higher the level of competitive (trait-state) anxiety is, the weaker the performance of athletes in competitions would be (7). Initial studies on anxiety were based on the assumption that anxiety is singledimensional. Spielberger (1966) was the first who divided anxiety into two dimensions of trait anxiety and state anxiety (8). Davidson and Schwartz (1976) proposed the theory of multidimensionality of anxiety and athletic performance which describes a series of two-way communication between cognitive anxiety, somatic anxiety, self-confidence, and performance. Cognitive component of anxiety includes subjective anxiety, negative evaluation, and negative expectations of performance, while somatic anxiety involves sweating, trembling, and increased heart rate (9).

Nowadays, sports sciences researchers have found the importance of understanding the role of psycho-motor skills in athletes and evaluation of these skills is a very important part of education, screening, talent finding, and championship. One of the psycho-motor skills that is involved in most sports is kinesthetic differentiation in athletes (10). Kinesthetic differentiation refers to a set of information resulting from the mechanoreceptors (muscle spindle, Golgi tendon organ, pacinian corpuscle, and free nerve terminals) in the dynamic mode (11). Kinesthetic differentiation has a strong relationship with precision in performing the tasks, as precise performance of a movement determines the winner and loser in many competitions (12). Since kinesthesia or proprioception has a prominent role in optimal performance of sports skills, regular physical activity is one of the important strategies to enhance proprioception. Exercise can improve proprioceptive systems that work to stabilize the body. Bressel, Yonker, and Kras (2007) showed that kinesthesia is stronger in footballers 
than the athletes in other sports and nonathletes (13). In fact, kinesthesia makes it possible to us to perceive the organ movement, allows us to perceive, regulate, and produce force for muscles and also to perceive the efforts made during the production of muscle force, and creates a sense of orientation and perception of limb position which is very important in setting the desired angle of joints when performing a task. Successful performance of many athletic skills like shooting in basketball and targeting in shooting requires precise adjustment of the force and hand angle (14). Kinesthesia makes it possible to understand the features of a movement and correct it based on the goals and motor needs. The ability to maintain and produce optimal force, in addition to technical benefits in sport, affects the economy of movement. Also, recent studies have demonstrated that kinesthesia is effective in rehabilitation and prevention of injury in athletes (10). Recent research evidence shows that conscious control of force production can be affected by the temporary mental condition of individuals (15), because, according to the findings of behavioral studies, motor and emotional neural circuits are anatomically and functionally very close to each other (16). The incidence of emotional states and anxiety can increase the range of conscious force production and also the excitability of cortical-spinal motor pathway. High load emotional changes can lead to damage and dysfunction (17). Hand movements in sports like table tennis where hand kinesthesia is the key factor of success are complex skills that are dependent on precise muscle control and various psychological and perceptualcognitive factors are involved in their performance (18). Although abovementioned evidence suggests that kinesthesia is influenced by mental states of individuals, the relationship between components of kinesthetic differentiation with psychological characteristics of people, especially athletes is still unknown (19). Anxiety is one of these factors. Given the paucity of studies on kinesthesia and its relationship with trait and state anxiety, the present paper aims to study the relationship of trait and state anxiety with kinesthesia in male athlete and non-athlete students.

\section{MATERIALS AND METHODS}

The present research was a fundamental retrospective study.

Participants. tatistical population included all male undergraduate students of Faculty of Humanities at Arak University in the academic year 2012-2013 ( $\mathrm{N}=2500)$. After distributing a personal information questionnaire among the population members, 200 students (100 athletes and 100 non athlete), with a mean age of $21.80 \pm 1.94$, were randomly selected as the sample. Criteria for entering the athlete groups included a minimum of 6 years of experience in sport and membership in one of the official clubs or membership in one of the sports teams of the university. Also, members of non-athlete group were selected among students who had no history of sport and regular physical activity.

Tools. The required data were collected using questionnaires of personal information and trait-state anxiety, tests of controlling the force and adjusting the angle of dominant hand, and a darts competition. Here is a short description of data collection tools:

1. Personal information questionnaire: This questionnaire included questions regarding participants' demographic characteristics such as age, height, weight, gender, level of physical activity per week, and sport history.

2. Spielberger State-trait Anxiety Inventory (STAI): The questionnaire was developed by Spielberger et al. (1970) and revised in 1983. It contains 40 items (20 items for trait anxiety and 20 items for state anxiety) and the respondents can express 
their feelings by score 1 (no anxiety) to 4 (high anxiety). The minimum and maximum score that a respondent can obtain on this inventory is 20 and 80 , respectively. The reliability of this tool has been reported by Spielberger et al. to be 0.86 for university students (8). In Iran, Panahi calculated the internal consistency and reliability of this questionnaire equal to $0.78-0.91$ and 0.67 by Cronbach's alpha coefficient and retest methods, respectively (20).

3. Zhukovski's dominant hand's angle accommodation test (1988): To measure kinesthesia, Zhukovski's dominant-hand's angle accommodation device was used. This device was developed in 1988 in the former Soviet Union and introduced for assessment of psychomotor performance of athletes. Reliability of this test was obtained 0.75 by Cronbach's alpha coefficient and its validity was reported acceptable by Bahrami (2010) (18). To perform this test, the elbow of dominant hand of subjects was placed on the apex of the device at a maximum angle 90 degrees. In order to get familiar with test, all subjects performed it three times with the help of the examiner and visual feedback. Then, the test was taken from each subject for three other times. The mean score of three times was considered as the absolute error figure. Starting angle was determined by the examiner in all times. The test was done in a way that the degrees of freedom for all of them was complete and there was no motor limitation.

4. Ablacova's force control of dominant hand test (1990): To measure force control of dominant hand, Ablacova's test was done using a standard isometric hand-held dynamometer. This device measures the force in the range of 0 to 100 with an accuracy of $1 \mathrm{~kg}$. Reliability and validity of this test has been reported acceptable. To perform this test, the subjects were asked to stand on feet as their hands are besides their body and they feet are open as much as the shoulder width. The subjects were expected to keep the dynamometer in their dominant hand parallel to their body with an angle of 90 degrees, as the scale sheet is on the opposite side of their body. Then, they were asked to press the dynamometer's handle without moving the hand based on the amount of force required by the examiner. This test was taken 3 times from each subject without visual feedback and with 10 seconds of rest between attempts. The mean score of three times was considered as the absolute error.

Procedure. Before beginning the study, all the arrangements were coordinated with the Faculty of Humanities, Arak University. In a meeting, the test were explained to all subjects and they were briefed on research procedure. Then, the subjects were asked to fill out the first part of Spielberger State-trait Anxiety Inventory. On the day of an official darts competition, kinesthesia tests were firstly performed and then the subjects were asked to fill out the second part of Spielberger State-trait Anxiety Inventory 10 minutes before the competition. In order to induce anxiety in a competitive environment, appropriate awards were considered for those who ranked first to third (1000000 Rials for the first one, 700000 Rials for the second one, and 500000 Rials for the third one). Motivation level of participants and competitive environment were two of the limitation of this research.

Statistical Analysis. Descriptive statistics, Kolmogorov-Smirnov test, Pearson correlation test, Durbin-Watson test, ANOVA, and simultaneous multiple regression were used for analyzing the collected data in SPSS software. Data analysis was performed using the SPSS software at a significance level of 0.05 . 


\section{RESULTS}

The data on the subjects' scores in trait anxiety, state anxiety, general anxiety, and kinesthesia error are shown briefly in Table 1 . Matrix of correlation between the studied variables is shown in Table 2. Simultaneous multiple regression analysis was used to study the relationship between components of anxiety and kinesthesia error (Tables 3,4). The results of comparing two athlete and non-athlete groups in terms of trait anxiety are shown in Table 5.

Table 1. Descriptive statistics for studied variables in both athlete and non-athlete groups

\begin{tabular}{cccc}
\hline Variable & Group & $\mathbf{n}$ & Mean \pm SD \\
\hline \multirow{2}{*}{ Trait anxiety } & Athlete & 100 & $42.80 \pm 1.76$ \\
& Non-athlete & 100 & $52.80 \pm 2.28$ \\
\hline \multirow{2}{*}{ State anxiety } & Athlete & 100 & $46.10 \pm 1.48$ \\
General anxiety & Non-athlete & 100 & $63.60 \pm 4.13$ \\
\hline \multirow{2}{*}{ dominant hand's angle } & Athlete & 100 & $44.45 \pm 1.40$ \\
accommodation error & Non-athlete & 100 & $57.90 \pm 3.20$ \\
\hline force control of & Athlete & 100 & $2.40 \pm 1.04$ \\
dominant hand error & Non-athlete & 100 & $7.60 \pm 1.90$ \\
\hline Overall error of & Athlete & 100 & $2.54 \pm 0.96$ \\
kinesthesia & Non-athlete & 100 & $4.64 \pm 1.00$ \\
\hline
\end{tabular}

According to Table 1, athletes have a lower level of state anxiety, trait anxiety, and kinesthesia error than non-athletes. Based on the mean values of the two groups, scores of overall error of kinesthesia, state anxiety, trait anxiety, and general anxiety are higher in non-athletes.

Table 2. The relationship of state and trait anxiety with force control and dominant hand's angle accommodation

\begin{tabular}{ccccccc}
\hline & $\begin{array}{c}\text { Trait } \\
\text { anxiety }\end{array}$ & $\begin{array}{c}\text { State } \\
\text { anxiety }\end{array}$ & $\begin{array}{c}\text { General } \\
\text { anxiety }\end{array}$ & $\begin{array}{c}\text { dominant hand's } \\
\text { angle } \\
\text { accommodation } \\
\text { error }\end{array}$ & $\begin{array}{c}\text { force } \\
\text { control of } \\
\text { dominant } \\
\text { hand error }\end{array}$ & $\begin{array}{c}\text { Overall } \\
\text { error of } \\
\text { kinesthesia }\end{array}$ \\
\hline Trait anxiety & 1 & $0.97^{* *}$ & $0.99^{* *}$ & $0.96^{* * *}$ & $0.86^{* *}$ & $0.96^{* *}$ \\
\hline State anxiety & 1 & $0.90^{* *}$ & $0.97^{* *}$ & $0.86^{* *}$ & $0.96^{* *}$ \\
\hline $\begin{array}{c}\text { General anxiety } \\
\text { dominant hand's } \\
\text { angle } \\
\text { accommodation } \\
\text { error }\end{array}$ & & 1 & $0.97^{* *}$ & $0.81^{* *}$ & $0.96^{* *}$ \\
\hline $\begin{array}{c}\text { force control of } \\
\text { dominant hand } \\
\text { error }\end{array}$ & & & & & $0.79^{* *}$ & $0.97^{* *}$ \\
\hline $\begin{array}{c}\text { Overall error of } \\
\text { kinesthesia }\end{array}$ & & & & & \\
\hline
\end{tabular}

According to Table 2, the results of Pearson correlation test indicated that there is a strong positive correlation between trait anxiety and state anxiety $(\mathrm{p}=0.001, \mathrm{r}=0.97)$.
This means that an increase in trait anxiety leads to increased state anxiety. There is also a significant positive correlation between overall error of kinesthesia and trait anxiety 
$(\mathrm{p}=0.001, \mathrm{r}=0.95)$ and also between overall positive correlation can be observed between error of kinesthesia and state anxiety $(\mathrm{p}=0.001, \mathrm{r}=0.96)$. In addition, a strong overall error of kinesthesia and general anxiety $(\mathrm{p}=0.001, \mathrm{r}=0.96)$.

Table 3. A summary of simultaneous multiple regression analysis

\begin{tabular}{ccccc}
\hline Index model & $\mathrm{R}$ & $\mathrm{R}^{2}$ & $\mathrm{~F}$ & $\mathrm{p}$ \\
\hline Regression & 0.96 & 0.93 & 251.21 & $0.001^{* *}$ \\
\hline & $* *$ : significant level at $\mathrm{p}<0.01$.
\end{tabular}

According to the results of Table 3, The $\mathrm{R}$ value obtained in this analysis (0.96) suggests a strong positive correlation between criterion variable (kinesthesia) and predictor variables (state and trait anxiety). Based on the F-value obtained (251.21), which is statistically significant at a significance level of 0.01 , it can be stated that there is a linear relationship between components of anxiety and kinesthesia $(\mathrm{p}=0.001)$.

Table 4. Simultaneous multiple regression of anxiety and kinesthesia

\begin{tabular}{ccccc}
\hline Index variable & $\mathrm{B}$ & Beta & $\mathrm{T}$ & $\mathbf{p}$ \\
\hline Trait anxiety & 0.17 & 0.42 & 2.11 & 0.042 \\
\hline State anxiety & 0.12 & 0.54 & 2.68 & 0.11 \\
\hline & $*$ : significant level at $\mathrm{p}<0.05$.
\end{tabular}

As Table 4 shows, given the significance level, state anxiety can predict the variations in kinesthesia error $(\mathrm{p}=0.011)$. State anxiety has the lion share in the explanation of kinesthesia error variance, as its standard beta coefficient is more than that of trait anxiety. The standardized coefficient of regression obtained for state anxiety (0.54) indicates that one unit of change in state anxiety leads to a change of 0.54 in kinesthesia error. Given the positive value of regression beta coefficient for state anxiety, an increase in state anxiety causes an increased in kinesthesia error. Also, according to the regression beta coefficient for trait anxiety (0.42) and its significance level $(0.41)$, it can be stated that trait anxiety can be a good predictor of kinesthesia error after state anxiety. The standardized coefficient of regression obtained for trait anxiety (0.42) suggests that one unit of change in this variable leads to a change of 0.42 in kinesthesia error.

Table 5. ANOVA of in two groups of athletes and non-athletes

\begin{tabular}{ccc}
\hline Variables & $\mathbf{F}$ & $\mathbf{p}$ \\
\hline Trait anxiety & 1.10 & $0.001^{* *}$ \\
\hline State anxiety & 1.65 & $0.001^{* *}$ \\
\hline General anxiety & 1.54 & $0.001^{* *}$ \\
\hline Dominant hand's angel accommodation error & 1.53 & $0.001^{* *}$ \\
\hline Force control of dominant hand error & 263.32 & $0.001^{* *}$ \\
\hline Overall error of kinesthesia & 587.07 & $0.001^{* *}$ \\
\hline
\end{tabular}

$* *$ : significant level at $\mathrm{p}<0.01$

According to the Table 5, there is a significant difference between athletes and non-athletes in trait anxiety. Also, a significant difference was observed between two groups in terms of state anxiety $(p=0.001)$. As Table 5 shows, there is a 
significant difference between athlete and non-athlete groups in terms of general anxiety and also overall error of kinesthesia $(\mathrm{p}=0.001)$. In addition, $\mathrm{F}$ values in all studied variables suggest a significant relationship between them.

\section{DISCUSSION AND CONCLUSION}

The present paper aimed to study the relationship of state and trait anxiety with kinesthesia in athlete and non-athlete male students. Given that no study has been conducted on this subject, anxiety and kinesthesia were examined in the studied groups by holding an official darts competition in the university. Generally, the results showed that athletes have a better condition than non-athletes in trait and state anxiety and kinesthesia. Also, a significant linear relationship and strong correlation was observed between state anxiety and trait anxiety. The results are consistent with most of studies which reported lower levels of trait and state anxiety in athletes (4-23). When a person with high trait anxiety is in a threatening situation, state anxiety also increases. Eysenck and Calvo (1992) argue that state anxiety occurs in threatening situation and is mutually influenced by trait anxiety and situational stress. In this case, one is not able to arouse a pattern of behavior in order to overcome or change the event or issue that is threatening the goals (21). Comparison of studied variables showed that there is a significant difference between athletes and non-athletes in terms of trait and state anxiety and kinesthesia. This is consistent with the findings of Shahbazi et al. (2012) who reported that there is a significant negative correlation between intelligence and selective reaction time and between state anxiety and selective reaction time. They also found a significant relationship between simple reaction time and trait anxiety (23). Also, Hainaut and Bolmont (2006) points out that state anxiety increases muscle tension, arousal, and thereby focus of attention, which regulates sensory processing. In his study, individuals with normal (not low) trait anxiety recovered in the condition stimulating state anxiety on visual response time. Improved performance in response to visual stimuli may be probably due to more arousal and attention paid to the relevant visual stimuli, as individuals with low trait anxiety pay attention to the auditory stimuli and showed an improved performance (22). This is consistent with the results of present study.

Robazza, Bortoli, and Nougier (1998) studied the relationship between anxiety and performance of members of the Italian national Archery team and concluded that there is a relationship between high anxiety and weak performance (4), which confirms the findings of this study. Therefore, it can be stated that results of the present study in this part are consistent with the findings of some studies which have attributed better performance in skills requiring high precision to low arousal. Hainaut and Bolmont (2006), Robazza, Bortoli, and Nougier (1998), Collette and Van der Linden (2002), and Eysenck and Calvo (1992) came to the conclusion in their studies that anxiety creates inefficiency and anxious individuals increase the use of compensatory strategies $(4,21,22,24)$. This is consistent with the findings of the present study. Study findings also indicated that there is a significant different between two studied groups in state anxiety and kinesthesia error and state and trait anxiety can predict kinesthesia error, but the contribution of state anxiety is more. The findings also suggested that state anxiety of athletes is in an optimal and medium level. This is in line with inverted $\mathrm{U}$ principle which associates optimal performance with medium anxiety. In addition, Bandura's theory of self-efficacy, according to which thinking pattern and emotional and behavioral reactions are influenced by stressful situations, confirms the results of this study. The findings also 
corroborate the positive effect of exercise on improving kinesthesia and suggest that athletes make fewer kinesthetic errors because they enjoy a good performance in information processing (14).

The results of the present study are also consistent with the findings of Tod, Iredale and Gill (2003), Tod et al. (2005), and Coombes et al. (2009). The recent research evidence shows that conscious control of force production can be influenced by the temporary mental condition (15). Also, motor and emotional neural circuits are anatomically and functionally very close to each other (16). The incidence of emotional states and anxiety can increase the range of conscious force production and also the excitability of cortical-spinal motor pathway (17). It should be also noted that kinesthetic differentiation has a strong relationship with precision in performing the tasks, as precise performance of a movement determines the winner and loser in many competitions (12).

Weinberg and John (1978), in a study entitled "Motor Performance Under Three Levels of Trait Anxiety and Stress" on male students, observed that increased arousal caused by conversion of low stress into medium stress caused improved performance, but further increase of arousal in high stress condition reduced proficiency in motor function (6). This is consistent with the results of the present study where nonathletes who had higher level of stress showed weaker motor performance.
It can be generally deducted that there is a significant relationship between anxiety and kinesthesia and athletes enjoy a better kinesthesia, which is one of the key factors for success in sports. Thus, it is recommended that coaches and sports teachers and psychologists use psychomotor tests as a valuable and effective tool for achieving the goals of sports indifferent aspects of education, screening, talent finding, and championship. In addition, qualitative and quantitative evaluation of athletic skills through tests makes it possible to design and plan appropriate training programs, because one of the problems that Iran's sports community is now dealing with is the lack sufficient knowledge about the design and planning of appropriate and modern training sessions in the least desirable and modern training in the shortest time.

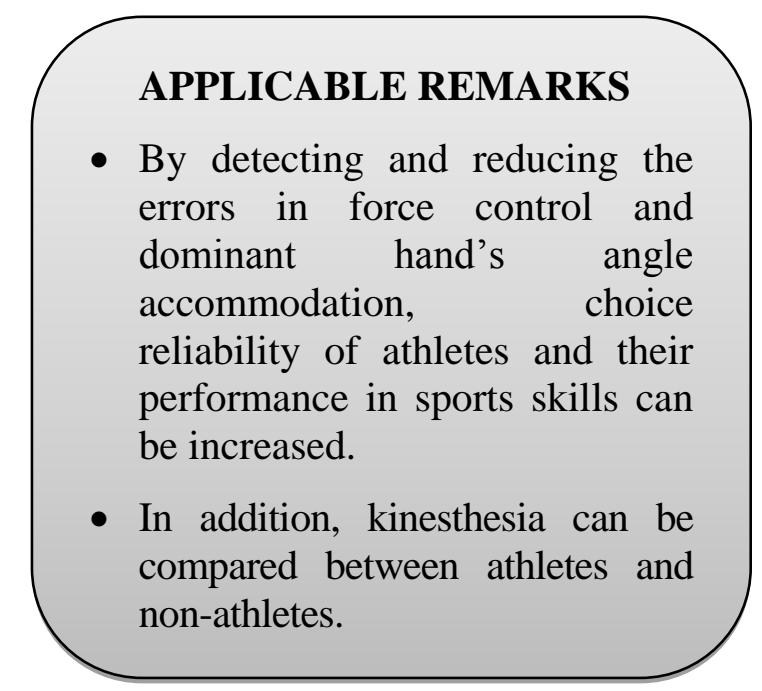

\section{REFFRENCES}

1. Ramezaninejad R, Sadeghi A, Ofoghi N, Khaleghi H A. Comparison of Sport Orientation in Athlete Students in University of Gilan. Harakat. 2005(24):59-72 [Article in Farsi].

2. Cheraghi F, Moradi A, Farahani MN. The Effect of Trait Anxiety and Stressful Conditions on the processing Efficiency and Working Memory Performance. Journal of Behavioral Sciences. 2008;2(1):25-32 [Article in Farsi].

3. Williams L. Motivational Orientations: Achievement and Competitiveness. In: Gill DL, Williams L, editors. Psychological dynamics of sport and exercise. 3rd ed: Human Kinetics; 2008.

4. Robazza C, Bortoli L, Nougier V. Physiological arousal and performance in elite archers: A field study. European psychologist. 1998;3(4):263.

5. Martens R, Vealey RS, Burton D. Competitive Anxiety in Sport: Human Kinetics Books; 1990. 277 p.

6. Weinberg RS, John R. Motor Performance Under Three Levels of Trait Anxiety and Stress. Journal of Motor Behavior. 1978;10(3):169-76. 
7. Grossbard JR, Cumming SP, Standage M, Smith RE, Smoll FL. Social desirability and relations between goal orientations and competitive trait anxiety in young athletes. Psychology of Sport and Exercise. 2007;8(4):491505.

8. Vitasari P, Wahab MNA, Herawan T, Othman A, Sinnadurai SK. Re-test of State Trait Anxiety Inventory (STAI) among engineering students in Malaysia: reliability and validity tests. Procedia-Social and Behavioral Sciences. 2011;15:3843-8.

9. Davidson RJ, Schwartz GE. The psychobiological of relaxation and related states: A multiprocess theory. In: Mostofsky DI, editor. Behavior Control and Modification of Physiological Activity: Prentice-Hall; 1976. p. 399442.

10. Rosker J, Sarabon N. Kinaesthesia and Methods for its Assessment: Literature Review. ssr. 2010;19(5-6):165208.

11. Moslemi Haghighi F, Ghafari Nejad F. Comparison of the proprioception sense of ankle joint between 20-30 years old healthy non-athletic women and athletic women with jogging and non- jogging exercises. Koomesh. 2006;7(1):13-8 [Article in Farsi].

12. de Souza FA, Franciulli PM, Bigongiari A, Araújo RC, Pozzo R, Amadio AC, et al., editors. The effect of fatigue and visual feedback on submaximal isometric muscle contractions. 25 International Symposium on Biomechanics in Sports; 2007; Ouro Preto - Brazil.

13. Bressel E, Yonker JC, Kras J, Heath EM. Comparison of static and dynamic balance in female collegiate soccer, basketball, and gymnastics athletes. Journal of athletic training. 2007;42(1):42-6.

14. Magill RA, Anderson D. Motor learning and control: Concepts and applications: McGraw-Hill New York; 2007.

15. Tod D, Iredale F, Gill N. 'Psyching-up'and muscular force production. Sports Medicine. 2003;33(1):47-58.

16. Tod DA, Iredale KF, Mcguigan MR, Strange DEO, Gill N. "Psyching-Up" Enhances Force Production during the Bench Press Exercise. The Journal of Strength \& Conditioning Research. 2005;19(3):599-603.

17. Coombes SA, Tandonnet C, Fujiyama H, Janelle CM, Cauraugh JH, Summers JJ. Emotion and motor preparation: a transcranial magnetic stimulation study of corticospinal motor tract excitability. Cognitive, Affective, \& Behavioral Neuroscience. 2009;9(4):380-8.

18. Bahrami A, editor Standardization of psychomotor test, force control and accommodation of dominant hand's angle in students of Arak universities. 7th International Congress on Physical Education and Sport Sciences; 2010; Tehran, Iran: Sport Sciences Research Institute of Iran.

19. Coombes SA, Corcos DM, Pavuluri MN, Vaillancourt DE. Maintaining force control despite changes in emotional context engages dorsomedial prefrontal and premotor cortex. Cerebral cortex. 2012;22(3):616-27.

20. Panahi. A preliminary study on the validity, reliability and norms tracking for inventory of state - trait anxiety (STAI-Y). Tehran, Iran: Tarbiat Modares University; 1994 [Thesis in Farsi].

21. Eysenck MW, Calvo MG. Anxiety and Performance: The Processing Efficiency Theory. Cognition and Emotion. 1992;6(6):409-34.

22. Hainaut JP, Bolmont B. Moderate state-anxiety differently modulates visual and auditory response times in normal- and very low trait-anxiety subjects. Neuroscience Letters. 2006;395(2):129-32.

23. Shahbazi M, Pashabadi A, Abedini Parizi H. Relationship between State and Trait Anxiety, Reaction Time and IQ in Elite, Sub-Elite Athletes and Non-Athletes. Journal of Motor Learning and Movement. 2012;3(2):65-80 [Article in Farsi].

24. Collette F, Van der Linden M. Brain imaging of the central executive component of working memory. Neuroscience and biobehavioral reviews. 2002;26(2):105-25. 
تازههاى علوم كاربردى ورزش

مقاله اصيل

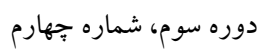

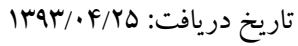

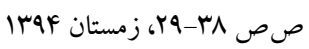

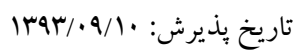

\title{
رابطه ميان اضطراب صفتى و حالتى با كنترل نيرو و تنظيم زاويه دست برتر در دانشجويان يسر
}

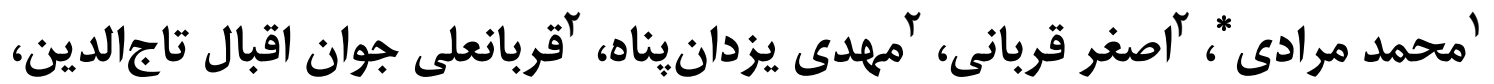

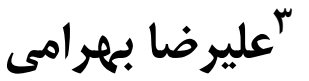

\author{
1. كارشناسى ارشد رفتار حركتى، دانشكده تربيت بدنى و علوم ورزشى، دانشخاه اراك، اراك، ايران.

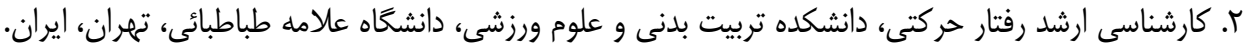

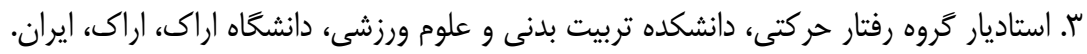

جكيده

هدف مطالعه حاضر بررسى رابطه اضطراب صفتى و حالتى با كنترل نيرو و تنظيه زاويه دست برتر در دانشجويان بِر ورزشكار و غيرورزشكار

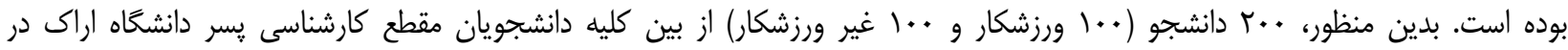

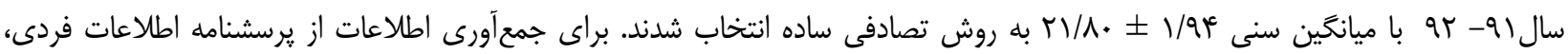

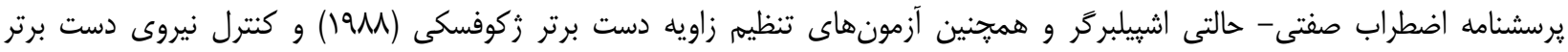

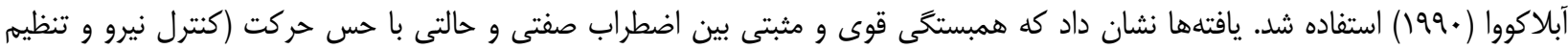

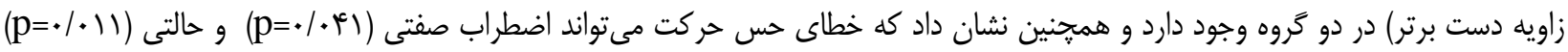

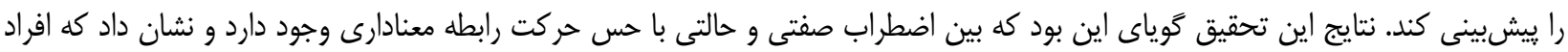

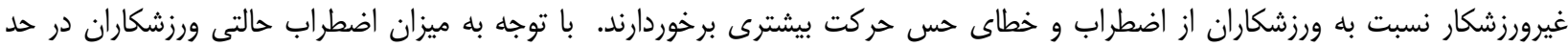

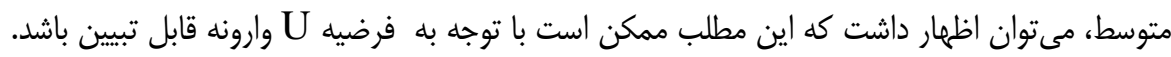
وازَّان كليدى: حس حركت، فرضيه U وارونه، اسكى، اضطراب صفتى، اضطراب حالتى. 